\title{
Effects of radiation therapy on the structure and function of the pelvic floor muscles of patients with cancer in the pelvic area: a systematic review
}

Stéphanie Bernard, Marie-Pier Ouellet, Hélène Moffet, Jean-Sébastien Roy, Chantale Dumoulin

\section{Abstract \\ Purpose}

Radiation therapy (RT) is often recommended in the treatment of pelvic cancers. Following RT, a high prevalence of pelvic floor dysfunctions (urinary incontinence, dyspareunia, and fecal incontinence) is reported. However, changes in pelvic floor muscles (PFMs) after RT remain unclear. The purpose of this review was to systematically document the effects of RT on the PFM structure and function in patients with cancer in the pelvic area.

Methods

An electronic literature search using Pubmed Central, CINAHL, Embase, and SCOPUS was performed from date of inception up to June 2014. The following keywords were used: radiotherapy, muscle tissue, and pelvic floor. Two reviewers selected the studies in accordance with Preferred Reporting Items for Systematic Reviews and Meta-Analyses Statement (PRISMA). Out of the 369 articles screened, 13 met all eligibility criteria. The methodological quality was assessed using the QualSyst scoring system, and standardized mean differences were calculated.

Results

Thirteen studies fulfilled all inclusion criteria, from which four were of good methodological quality. One presented strong evidence that RT affects PFM structure in men treated for prostate cancer. Four presented high-level evidence that RT affects PFM function in patients treated for rectal cancer. Meta-analysis was not possible due to heterogeneity and lack of descriptive statistics.

Conclusion

There is some evidence that RT has detrimental impacts on both PFMs' structure and function. Implications for cancer survivors

A better understanding of muscle damage and dysfunction following RT treatment will improve pelvic floor rehabilitation and, potentially, prevention of its detrimental impacts. 
Keywords

Literature review

Pelvic cancer

Radiation therapy

Pelvic floor disorders

Pelvic floor muscles

Cancer survivorship

\section{Introduction}

Pelvic cancers, such as urogynecological and colorectal cancers, are common afflictions. Colorectal cancers account for $13 \%$ of all new cancer diagnoses in Canada. For men, prostate cancers account for $25 \%$ of all new cases, while in women, gynecological cancers account for 13 $\%$ [1]. Radiation therapy is often recommended in the treatment of such cancers. It can be used pre-operatively and/or post-operatively in order not only to treat the malignancy itself, but also to decrease the risk of recurrence. Adjuvant radiation can be administered externally (external beam radiation therapy) or intra-cavitary by probe or radioactive implants (brachytherapy) [2] There are direct and indirect effects of radiation to the pelvic organs and musculature. Lesions such as stenosis, agglutination, or shortening of the vagina have been detailed for women after gynecological cancers [3]. Furthermore, a high prevalence of pelvic floor dysfunctions following radiotherapy for pelvic neoplasms has also been reported: urinary incontinence and urgency [4, 5], sexual dysfunction and dyspareunia [6-8], and fecal urgency and incontinence $[9,10]$. Such dysfunctions have been demonstrated not only to cause distress to cancer survivors [11], but also to diminish their participation in activities of daily living and social activities, leading to an overall decreased quality of life [12].

The pelvic floor consists of a network of muscles and fascia, which are attached to the bony pelvis. The superficial muscles play an important role in sexual function (bulbospongiosus, ischiocavernosus muscles), somewhat not important role in supportive function (transverse perineal muscles, perineum body) and in fecal continence (external anal sphincter muscle). The intermediate layer is mostly important in maintaining urinary continence (compressor urethra muscle, external urinary sphincter, etc.). Lastly, the deep layer includes the levator ani muscles (pubococcygeus, ileococcygeus, ischiococcygeus, and puborectalis muscles) which are known to play an important role in supporting pelvic organ and maintain continence under increasing abdominal pressure [13]. Moreover, the urethra and the anus also have an internal sphincter, which are intrinsic muscle layers that also contribute to continence. Together, the pelvic floor muscles are highly regulated by complex autonomic and somatic mechanisms to fine-tune their contraction and relaxation sequence in order to maintain continence [14]. This is why, for people without a history of cancer, pelvic floor muscle rehabilitation is highly recommended to treat pelvic floor dysfunctions like urinary incontinence or urgency [15]. Recently, trials have been initiated to identify better treatment options for pelvic floor dysfunctions in women after gynecological cancer treatment. These studies reported, after intensive pelvic floor muscle 
rehabilitation, decreased urinary incontinence, decreased sexual dysfunctions, and improved quality of life, without adverse effects $[16,17]$. From instructing how to correctly contract the pelvic floor muscles and do the home exercises, to one-on-one biofeedback training sessions, pelvic floor physiotherapists played a crucial role in the rehabilitation process in these studies. However, little is known regarding objectivable muscle changes following radiation therapy. Ooi et al. [18] overviewed common complications after adjuvant therapies in the treatment of rectal cancers, and the authors did identify the need for further understanding of the pelvic floor and sphincter function. In order to improve the treatment approaches for these dysfunctions, it is imperative to have a better understanding of muscle tissue changes induced by radiation. Such changes can be described, using the International Classification of Functioning, Disability and Health (ICF model), as any impairments to the anatomical structure of the muscle tissues or to the physiological functions of the muscles relative to their power, tone, endurance, or other specified muscle functions [19]. For brevity, the short terms "structure" and "function" are used henceforth to refer to muscle changes. This article systematically reviews the documented effects of radiation therapy on the pelvic floor muscle (PFM) structure [19] and function in patients with cancer in the pelvic area (including gynecological, prostatic, or colorectal cancers) .

\section{Method}

Literature search

This review was conducted according to the Preferred Reporting Items for Systematic Reviews and Meta-Analyses Statement (PRISMA) [20]. A systematic search of the electronic databases Pubmed Central, CINAHL, Embase, and SCOPUS was conducted from date of inception up to June 2014. The word concepts used for the search were as follows: radiotherapy as the medical intervention and pelvic floor as the targeted muscles. Muscle tissue, as the targeted body tissue, was added to the search since there was a need for increased precision of the results. All the synonyms and associated subterms were combined using the operator "OR" and, afterward, were combined altogether with the other concepts by the operator "AND." Two reviewers (SB and MPO) independently screened the titles and the abstracts for each reference, according to the established inclusion and exclusion criteria. Consensus was obtained through discussion when there was disagreement. The articles retained for full-text review were screened again by the two reviewers to reassess further meeting of all eligibility criteria. Lastly, the reference lists of the eligible articles were screened to verify if additional suitable studies, not previously identified with the databases systematic search, would be found. Once included after full-text review, data and results were extracted with a standardized form including the following: study design, participants' characteristics (such as age, sex, type of cancer), radiation intervention, outcome measures, follow-up period, and main results of interest. The first reader extracted the data (SB), and the second reader (MPO) corroborated or completed it if data were missing. 


\section{Eligibility criteria}

The articles met the inclusion criteria if they had (1) at least one group of adults or elderly patients with a diagnosis of cancer in the pelvic area treated by/with radiotherapy and (2) an outcome measure for the PFM structure or function. The articles were excluded if they did not present original results or if they involved resection of the PFMs. No limits were applied for language, and no case of inaccessible translation occurred. No limits were applied regarding length of follow-up since short-term and long-term effects of radiotherapy have been outlined before [21]. No limits were applied to the type of pelvic cancer, since the maximal dose tolerance from these organs overlaps (ranging between 50 and $100 \mathrm{~Gy}$, with 60-70 Gy for most pelvic organs) and because vicinity to the PFMs is similar [22-24].

Assessment of methodological quality and meta-analysis

Since the eligible articles were mostly non-experimental studies (prospective, retrospective, cross-sectional studies, etc.), the quality assessment for evaluating primary research studies (QualSyst) was used to evaluate the methodological quality and the risk of bias of the included studies [25]. An overview of the checklist used for scoring can be found in Table 2. This assessment tool has been shown to be moderately reliable [25]. For this review, the first four authors met after independent assessment of two papers in order to ensure proper score allocation. Afterward, every included paper was subjected to the QualSyst criteria checklist by two independent raters. They met to compare scores and resolve differences. Since summary scores are not yet associated to different qualitative categories, we used the following index to categorize the results to the following: "excellent quality" for scores higher than $80.0 \%$, of "good quality" for scores between 65.0 and $80.0 \%$, of "moderate quality" for scores between 50.0 and $64.9 \%$, and of "low quality" for scores below $50.0 \%$. For the synthesis of results, metaanalytic tools such as effect sizes were used when possible, using means and standard deviations of irradiated subjects and their control values. When these statistics were not published, contact was attempted with the authors in order to obtain the necessary statistics. Afterward, standardized mean differences (SMD) were used as summary measure of the results of several independent studies to appreciate the magnitude of the impact of radiation therapy (RT) on specific variables characterizing PFM structure and function [26]. The interpretation of the calculated effect sizes (d) followed the guidelines proposed by Cohen [27].

\section{Results}

Characteristics of selected studies

Figure 1 summarizes the results of the literature search. Searches yielded 369 results, from which 243 records remained after duplicates were removed. Following screening of the abstracts and full-text review, 13 studies fulfilled all inclusion criteria. Only one randomized controlled trial could be included in the review since pre-radiation baseline measures were available for comparison to the post-radiation measures. The other articles were mostly cohort (6), cross-sectional (3), quasi-experimental (1), case series (1), and case-control (1) studies. Five 
of the selected articles included participants (men or women) with colorectal cancer and anal cancer, five included men with prostate cancer, one included men with both prostate and rectal cancer, and lastly, two included women with cervical cancer. From retrievable data, age for all participants ranged from 34 to 81 years old with a mean of 61.4 years old. There were 160 women compared to 532 men, for an approximate total of 692 participants (some data are missing from control groups to allow an exact sum). The mean time between radiation and assessment was 78 weeks. A brief description of study populations and RT protocols is provided in Table 1.

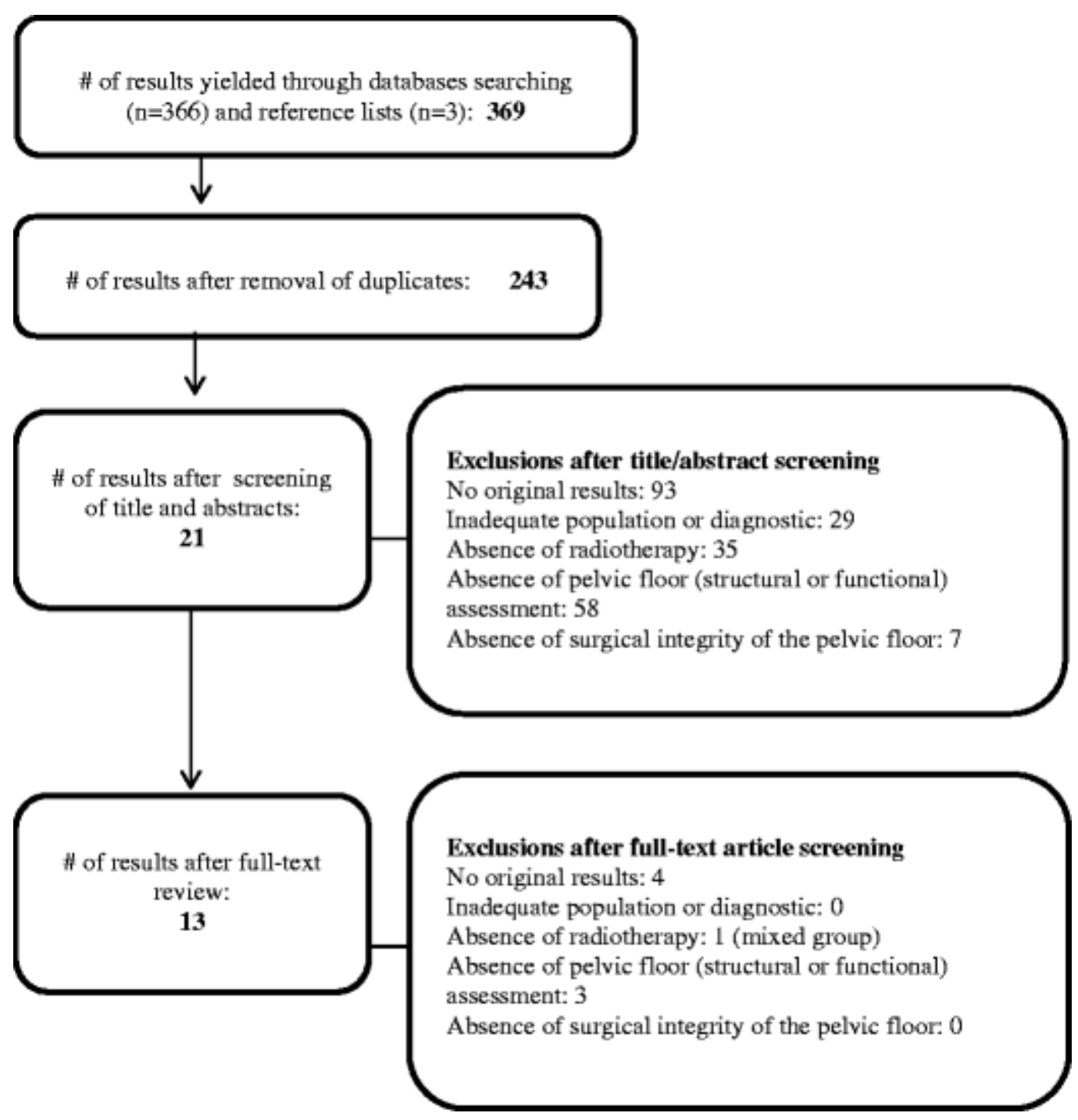

Fig. 1

PRISMA flowchart of the article selection process 
Table 1

Demographic data and RT protocols for studies included in the review

\begin{tabular}{|c|c|c|c|c|c|c|c|}
\hline & $\begin{array}{l}\text { Men } \\
(n)\end{array}$ & $\begin{array}{l}\text { Women } \\
(n)\end{array}$ & $\begin{array}{l}\text { Age } \\
\text { (years) }\end{array}$ & $\begin{array}{l}\text { BMI } \\
\left(\mathrm{kg} / \mathrm{m}^{2}\right)\end{array}$ & $\begin{array}{l}\text { RT } \\
\text { assessment } \\
\text { interval } \\
\text { (weeks) }\end{array}$ & $\begin{array}{l}\text { Type of } \\
\text { cancer }\end{array}$ & Type of RT \\
\hline$[\underline{28}]$ & 61 & 34 & 63.3 & 26.3 & 6 & Colorectal & $\begin{array}{l}\text { Post-operative, } \\
\text { total dose } \\
50.4 \pm 2 \mathrm{~Gy} \\
\text { (1.8 Gy five } \\
\text { times/week), } \\
\text { type of } \\
\text { radiation } \\
\text { unspecified }\end{array}$ \\
\hline [29] & - & - & $63^{a}$ & - & 113 & Anal & $\begin{array}{l}\text { Percutaneous } \\
\text { radiation } \\
\text { therapy was a } \\
\text { mean of } \\
56.1 \mathrm{~Gy} \\
\text { (for } n=21 \text { ), } \\
\text { and additional } \\
\text { BT for a mean } \\
\text { of } 7.2 \mathrm{~Gy} \text { in } 16 \\
\text { patients }\end{array}$ \\
\hline$[\underline{30}]$ & o & 24 & 63 & 24.9 & 416 & $\begin{array}{l}\text { Cervix } \\
\text { (mainly) }\end{array}$ & $\begin{array}{l}\text { EBRT (either } \\
\text { abdominal or } \\
\text { pelvic), total } \\
\text { dose between } \\
44 \text { and } 64 \text { Gy } \\
\text { during } 30 \text { to } \\
56 \text { days. }\end{array}$ \\
\hline [31] & 2 & o & - & - & 208 & $\begin{array}{l}\text { Prostate } \\
\text { and rectal }\end{array}$ & $\begin{array}{l}72 \mathrm{~Gy} \\
\text { administered }\end{array}$ \\
\hline
\end{tabular}




\begin{tabular}{|c|c|c|c|c|c|c|c|}
\hline & $\begin{array}{l}\text { Men } \\
(n)\end{array}$ & $\begin{array}{l}\text { Women } \\
\text { (n) }\end{array}$ & $\begin{array}{l}\text { Age } \\
\text { (years) }\end{array}$ & $\begin{array}{l}\text { BMI } \\
\left(\mathrm{kg} / \mathrm{m}^{2}\right)\end{array}$ & $\begin{array}{l}\text { RT } \\
\text { assessment } \\
\text { interval } \\
\text { (weeks) }\end{array}$ & $\begin{array}{l}\text { Type of } \\
\text { cancer }\end{array}$ & Type of RT \\
\hline & & & & & & & in 40 fractions \\
\hline [32] & 128 & o & 66.9 & - & 90 & Prostate & $\begin{array}{l}n=45 \\
\text { underwent } \\
\text { EBRT (median } \\
\text { dose, } \\
86.4 \text { Gy), } n=29 \\
\text { underwent BT } \\
\text { (median dose, } \\
\text { 144 Gy), } \\
\text { and } n=34 \\
\text { patients } \\
\text { underwent a } \\
\text { combination of } \\
\text { BT (median } \\
\text { dose for } \\
\text { iodine-125, } \\
\text { 110 Gy, for } \\
\text { palladium-103, } \\
\text { 10o Gy, and for } \\
\text { iridium-192, } \\
21 \text { Gy) and } \\
\text { EBRT (median } \\
\text { dose, } 50.4 \text { Gy) }\end{array}$ \\
\hline [33] & 35 & $\mathrm{O}$ & 68 & 26 & 5 & Prostate & $\begin{array}{l}\text { EBRT: } \\
\text { between } 55 \\
\text { and } 64 \mathrm{~Gy}, \\
\text { administered } \\
\text { during } 4 \text { to } \\
6.5 \text { weeks }\end{array}$ \\
\hline
\end{tabular}




\begin{tabular}{|c|c|c|c|c|c|c|c|}
\hline & $\begin{array}{l}\text { Men } \\
(n)\end{array}$ & $\begin{array}{l}\text { Women } \\
\text { (n) }\end{array}$ & $\begin{array}{l}\text { Age } \\
\text { (years) }\end{array}$ & $\begin{array}{l}\text { BMI } \\
\left(\mathrm{kg} / \mathrm{m}^{2}\right)\end{array}$ & $\begin{array}{l}\text { RT } \\
\text { assessment } \\
\text { interval } \\
\text { (weeks) }\end{array}$ & $\begin{array}{l}\text { Type of } \\
\text { cancer }\end{array}$ & Type of RT \\
\hline [34] & 34 & $\mathrm{O}$ & 68 & 26 & 72.8 & Prostate & $\begin{array}{l}\text { EBRT: } \\
\text { between } 55 \\
\text { and } 64 \mathrm{~Gy} \text {, } \\
\text { administered } \\
\text { during } 4 \text { to } \\
6.5 \text { weeks }\end{array}$ \\
\hline [35] & 35 & $\mathrm{O}$ & 59 & - & 52 & Prostate & $\begin{array}{l}\text { BT by seeds } \\
(125 \text { seeds } \\
\text { for } n=24 \text { and } \\
103 \text { seeds } \\
\text { for } n=11) \\
\text { For } n=7 \text {, there } \\
\text { was additional } \\
\text { EBRT }\end{array}$ \\
\hline [36] & $\mathrm{O}$ & 60 & 51.6 & 26.2 & 27 & Cervix & $\begin{array}{l}\text { Combination } \\
\text { of EBRT (dose } \\
\text { of } 45 \text { to } \\
50.4 \mathrm{~Gy} \text { ) and } \\
\text { intra-cavitary } \\
\text { BT, without } \\
\text { extended-field } \\
\text { irradiation }\end{array}$ \\
\hline [37] & 6 & 5 & 56.4 & - & 7 & Rectal & $\begin{array}{l}50-\mathrm{Gy} \\
\text { irradiation in } \\
25 \text { fractions } \\
\text { administered } \\
\text { over a 5-week } \\
\text { period } \\
\text { ( } 2 \text { Gy/fraction) }\end{array}$ \\
\hline
\end{tabular}




\begin{tabular}{|c|c|c|c|c|c|c|c|}
\hline & $\begin{array}{l}\text { Men } \\
(n)\end{array}$ & $\begin{array}{l}\text { Women } \\
\text { (n) }\end{array}$ & $\begin{array}{l}\text { Age } \\
\text { (years) }\end{array}$ & $\begin{array}{l}\text { BMI } \\
\left(\mathrm{kg} / \mathrm{m}^{2}\right)\end{array}$ & $\begin{array}{l}\text { RT } \\
\text { assessment } \\
\text { interval } \\
\text { (weeks) }\end{array}$ & $\begin{array}{l}\text { Type of } \\
\text { cancer }\end{array}$ & Type of RT \\
\hline [38] & 161 & $\mathrm{O}$ & 68.6 & $27 \cdot 3$ & 8 & Prostate & $\begin{array}{l}\text { IMRT with a } \\
\text { dose of } 78 \text { Gy } \\
\text { in } 39 \text { fractions } \\
\text { given in five } \\
\text { fractions per } \\
\text { week }\end{array}$ \\
\hline [39] & 39 & 27 & 63 & - & 4 & Rectal & $\begin{array}{l}45 \text { Gy } \\
\text { administered } \\
\text { in } 25 \text { fractions } \\
\text { ( } 5 \text { weeks): } \\
\text { for } n=26 \text {, } \\
\text { there was } \\
\text { EBRT, and } \\
\text { forn = 20, } \\
\text { there was } \\
\text { irradiation of } \\
\text { the superior } \\
\text { pelvis (anal } \\
\text { canal } \\
\text { excluded) }\end{array}$ \\
\hline [40] & $31^{\mathrm{a}}$ & $10^{\mathrm{a}}$ & $61^{\mathrm{b}}$ & - & 5 & Rectal & $\begin{array}{l}45 \text { Gy in } \\
\text { fractions at } \\
\text { 1.5 Gy per day } \\
\text { treated daily, } \\
5 \text { days a week }\end{array}$ \\
\hline
\end{tabular}

$B M I$ body mass index, $R T$ radiation therapy, $B T$ brachytherapy, $E B R T$ external beam radiation

therapy, IMRT intensity-modulated radiotherapy, Gy Gray, - unavailable data

aData from subgroup related to our variables of interest

'Only data from irradiated subjects, controls' characteristics unavailable 
The impact of RT on the PFM structure was studied in eight articles (Table 3). Muscle structure integrity was assessed using anal manometry (for sphincter length measurements), endoscopic ultrasound, MRI, and histology (microscopic) analysis. Ten papers reported results related to PFM function (Table 4). The tools and methods used for these measurements were manual muscle testing through digital palpation (Oxford Scale), anorectal perfusion manometry, and surface EMG (more details below). Five of the studies presented data related to both structure and function.

The effects of RT on PFM structure

Of the eight articles that studied PFM structure after RT, three compared the irradiated subjects to non-cancer, non-irradiated subjects [28-30], another one to a subject with cancer who did not receive radiation [31], and three compared to pre-radiation measures for their cohort study [32-34], and the last study had no control group [35]. In these studies, the effects of radiation were observed through evaluation of the changes in the muscle tissue itself, such as its dimension, morphology, or composition (Table 3). These articles were mostly of "good" quality, but one obtained $100 \%$ [32] on the quality assessment (Table 2). In the quasi-experimental study by Allgayer et al. [28], only the post-radiation measures assessed before an experimental exercise program were used, which were anal sphincter length measured by anal perfusion manometry, internal anal sphincter diameter, and external anal sphincter diameter measured by endoscopic ultrasound. Their results show no or weak effect (effect size 0.17 ) of radiation on sphincter length of men pre- to post-radiotherapy for colorectal cancer (Table 3). As the measures from the anal sphincter's diameters were not presented in the results by the authors, this article concludes to a non-significant impact of radiation on the muscle's structure solely from the anal sphincter's length measures. Similar measures were taken in a study by Vordermark et al. [29]. This paper did find a significantly shorter $(p=0.03)$ sphincter's length with irradiated subjects (no surgery) compared to healthy volunteers. The first study reviewed from Yeoh et al. [30] reported measures of maximal thickness for external and internal anal sphincters from anal ultrasound in cervical cancer patients. No significant differences were found between the subjects and healthy controls for these variables. The effect size for the maximal thickness of the external anal sphincter was in accordance with this result (effect size 0.14), but the effect size for the thickness of the internal anal sphincter suggests a moderate detrimental effect of RT (effect size -0.72). Similar conclusions were drawn from a prospective cohort study conducted by the same author; no differences were found between pre- and postradiation measures of maximal thickness of the external and internal anal sphincters in men treated for prostate cancer in acute [33] and chronic [34] conditions; however, no effect size could be calculated from available data. Another study by Gervaz et al. [31] presented an interesting case study with measures until 4 years post-radiation. On histology analysis, the presence of immunoreactivity of tumor growth factor $\beta 1$ (TGF- $\beta 1$ ) and connective tissue growth factor (CTGF) was significantly higher in anal sphincter strips from an irradiated subject than from a non-irradiated subject, especially in the smooth muscles cells. This translates into 
prolonged radiation-induced fibrosis into muscle tissues, especially in the smooth layer muscle cells. These findings support the hypothesis not only that radiation affects the muscle structure of the pelvic floor through increase fibrotic tissue, but also that these effects seem to be still ongoing 4 years after radiation. Furthermore, Coakley et al. [35] used MRI as a measurement tool to observe that $97.1 \%$ of their subjects presented with radiation-induced changes in the levator ani muscles, as demonstrated by increased signal intensity in these structures and 80.0 $\%$ in the urogenital diaphragm muscles after brachytherapy by radioactive implants. Along with these findings, Marigliano et al. [32] also used MRI to assess the radiation-induced changes in periurethral muscles and in periprostatic portion of the levator ani muscles and also measured the urethral length. The authors observed not only that there was a significant reduction of the urethral length pre- to post-radiation, but also that there was an increased signal intensity in the periurethral (in 70 to $86 \%$ of cases) and periprostatic portion of the levator ani (in 90 to $96 \%$ of cases) post-RT, suggesting fibrotic changes in these muscle tissues. These data show a moderate detrimental effect (effect size -0.65 ) of radiotherapy on the urethral length for men treated for prostate cancer (Table 3). Most of these data show a trend supporting the presence of changes in the PFM structure after RT in the treatment of prostate and colorectal cancer, except for anal sphincter thickness. Since our requests to obtain further precision on presented data remained unanswered by most authors and that two studies presented descriptive data in lieu of analytic data, only few effect sizes from SMD could be calculated. It was not possible to perform metaanalysis secondary to heterogeneity between structures under study and lack of descriptive statistics.

\begin{tabular}{|c|c|c|c|c|c|c|c|c|c|c|c|c|c|}
\hline \multirow[b]{2}{*}{ Criteria } & \multicolumn{13}{|c|}{ Articles } \\
\hline & [28] & [29] & [30] & [31] & [32] & [33] & [34] & [35] & [36] & [37] & [38] & [39] & [40] \\
\hline Objective & 2 & 1 & 2 & 2 & 2 & 2 & 2 & 2 & 2 & 2 & 2 & 2 & 1 \\
\hline Design & 2 & 1 & 2 & 1 & 2 & 2 & 1 & 2 & 1 & 2 & 2 & 2 & 1 \\
\hline Subject selection & 2 & 1 & 2 & 1 & 2 & 2 & 2 & 1 & 2 & 2 & 2 & 2 & 1 \\
\hline Subject characteristics & 2 & 0 & 2 & 1 & 2 & 2 & 2 & 2 & 2 & 1 & 2 & 2 & 0 \\
\hline Random allocation & - & - & - & - & - & 0 & 2 & - & - & - & 2 & - & - \\
\hline Blinding investigators & 0 & 0 & 0 & 0 & 2 & 0 & 0 & 2 & 0 & 2 & 1 & 0 & 0 \\
\hline Blinding subjects & - & - & - & - & - & - & - & - & - & - & - & - & - \\
\hline Outcome measures & 2 & 2 & 2 & 2 & 2 & 2 & 2 & 2 & 1 & 2 & 2 & 2 & 1 \\
\hline Sample size & 2 & 1 & 1 & - & 2 & 1 & 1 & 2 & 2 & 1 & 2 & 2 & 1 \\
\hline Analysis & 2 & 2 & 2 & - & 2 & 1 & 2 & 1 & 2 & 2 & 2 & 1 & 1 \\
\hline Variance & 2 & 1 & 2 & - & 2 & 2 & 2 & 0 & 2 & 2 & 2 & 2 & 2 \\
\hline Confounding & 0 & 0 & 0 & 1 & 2 & 1 & 1 & 1 & 0 & 1 & 2 & 2 & 0 \\
\hline Results & 2 & 2 & 2 & 2 & 2 & 2 & 2 & 1 & 2 & 2 & 2 & 2 & 2 \\
\hline Conclusions & 1 & 2 & 2 & 1 & 2 & 2 & 2 & 2 & 1 & 2 & 2 & 1 & 1 \\
\hline Summary score (points) & $19 / 24$ & $13 / 24$ & $19 / 24$ & $11 / 18$ & $24 / 24$ & $19 / 26$ & $21 / 26$ & $18 / 24$ & $17 / 24$ & $21 / 24$ & $25 / 26$ & $20 / 24$ & $11 / 24$ \\
\hline Summary score (\%) & 79.2 & 54.2 & 79.2 & 61.1 & 100.0 & 73.1 & 80.8 & 75.0 & 70.8 & 87.5 & 96.2 & 83.3 & 45.8 \\
\hline
\end{tabular}

Scoring detail: 2 , criteria are met; 1 , criteria are partially met; 0 , criteria are not met; -, if criteria are non-applicable, and therefore, criteria are excluded from summary score calculation 


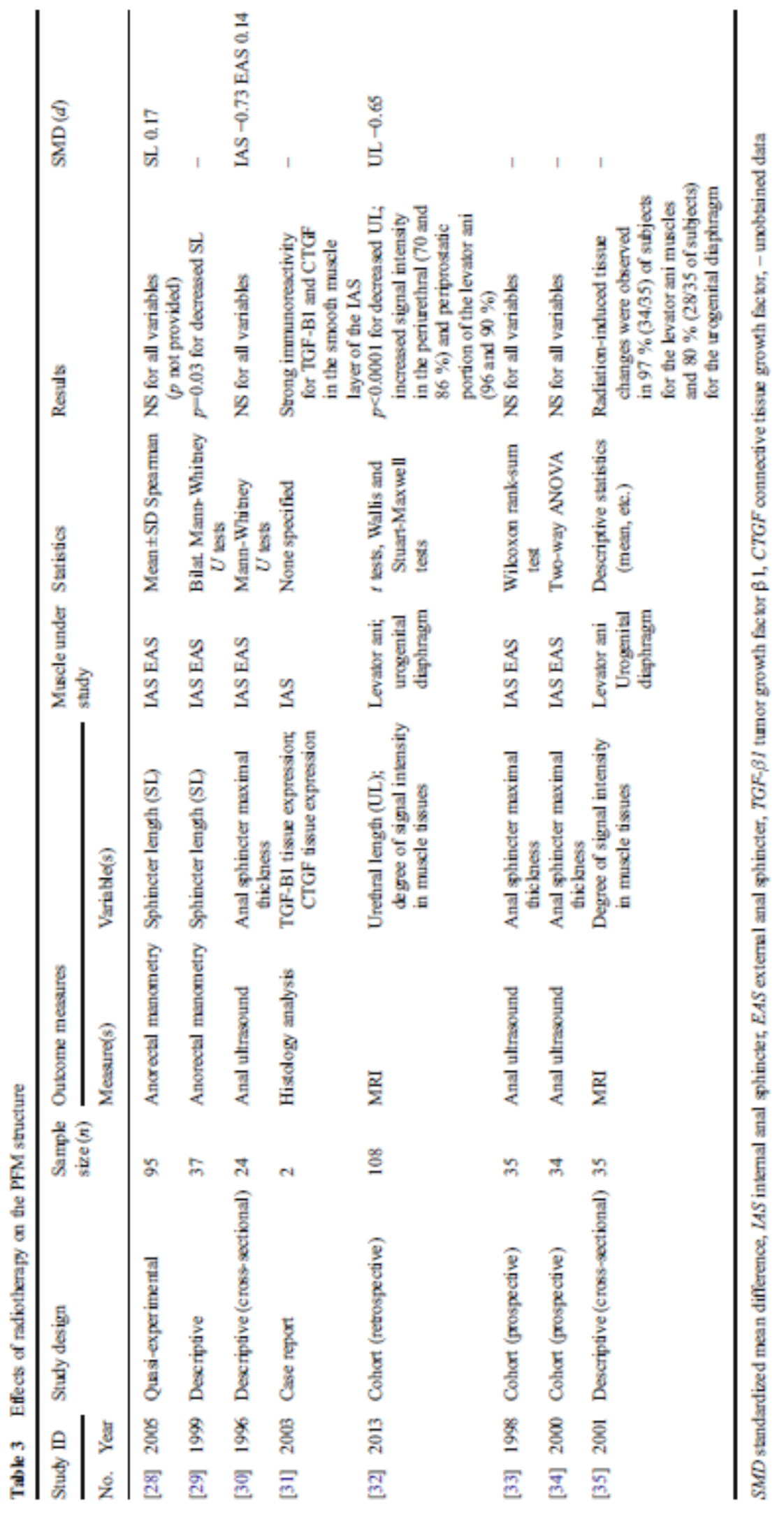


The effects of RT on PFM function

PFM strength

Seven articles presented data regarding pelvic floor's function. Two papers compared the irradiated subjects to non-cancer, non-irradiated subjects $[28,29]$ and two more to subjects with cancer but who did not receive radiation [36, 37], and three others compared to preradiation measures [38-40]. Two articles rated "Iow to moderate quality" [40, 29], two rated "good quality" [36, 28], and three of "excellent quality" [38, 39, 37] (Table 2). In a retrospective cohort study by Theisen et al. [40], resting and maximal squeeze pressure data measured by anal manometry was reported (Table 4). A significant decrease in the post-data compared to the pre-data was found for these two variables. Furthermore, the results of a cross-sectional study by Vordermark et al. [29] demonstrated a decreased anal resting and maximal squeeze pressure through manometry for the RT group compared to healthy normals. Manometry was also used in the studies by Yeoh et al. [30, 33, 34], where anal resting and maximal squeeze pressure were found decreased in chronic cervical cancer patients [30] 5 to 10 years post-RT compared to healthy volunteers. Strong detrimental effect sizes could be calculated from the data of the first study (between -0.94 and -1.3 ), except for resting pressure at anal sleeve where only a weak detrimental effect size was calculated (effect size -0.14), The same results were observed in a cohort of men treated for prostate cancer [33], between baseline and 4-6 weeks post-RT. However, these findings were not maintained after 1 year. In contrast, resting pressure was found to be increased with comparison to initial assessment [34], which the authors did not offer an explanation for. In their study, Allgayer et al. [28] did not observe significant difference between radiated and non-irradiated patients for anal resting and maximal squeeze pressure for the same outcome measure. Noronha et al. [36] demonstrated no significant difference between the surgical group $(\mathrm{RH})$ and the radiation groups for pelvic floor maximum strength, as measured by bidigital palpation. Still, a tendency toward a significant difference was obtained when comparing the RH and RT groups ( $p=0.06$ by omnibus test): we observed that the RT group appeared to have a greater proportion of extremely low maximum strength scores (such as 0 and 1) on the Oxford scale. Using R 3.0.0 software, we compared RH to RT for the proportion of these very low scores $(0,1)$ vs $(2,3,4,5)$ and a $p=0.03$ was obtained, meaning that the proportion of very low scores was significantly different between the RH and RT groups. This observation could be of clinical importance since incontinence was associated with the severity of the weakness of their pelvic floor [41]. Consequently, a trend toward a higher proportion of low-strength scores is likely for the subjects who received RT. Dieperink et al. [38], in 2013, presented a RCT where pre-RT baseline measures were available. With the collaboration of the authors, additional paired t tests (data available in Table 5) were conducted, and it was acknowledged that when measured digitally using the Oxford scale, maximal PFM contraction, static strength, and dynamic strength were not significantly different pre- to postradiation. Lastly, Lim et al. [39] presented short-term effects of preoperative chemoradiation on anorectal function using anorectal manometry. Mean maximum resting and maximum squeeze 
pressure were gathered, and maximum squeeze pressure was found to be highly significantly decreased $(p<0.0001)$.

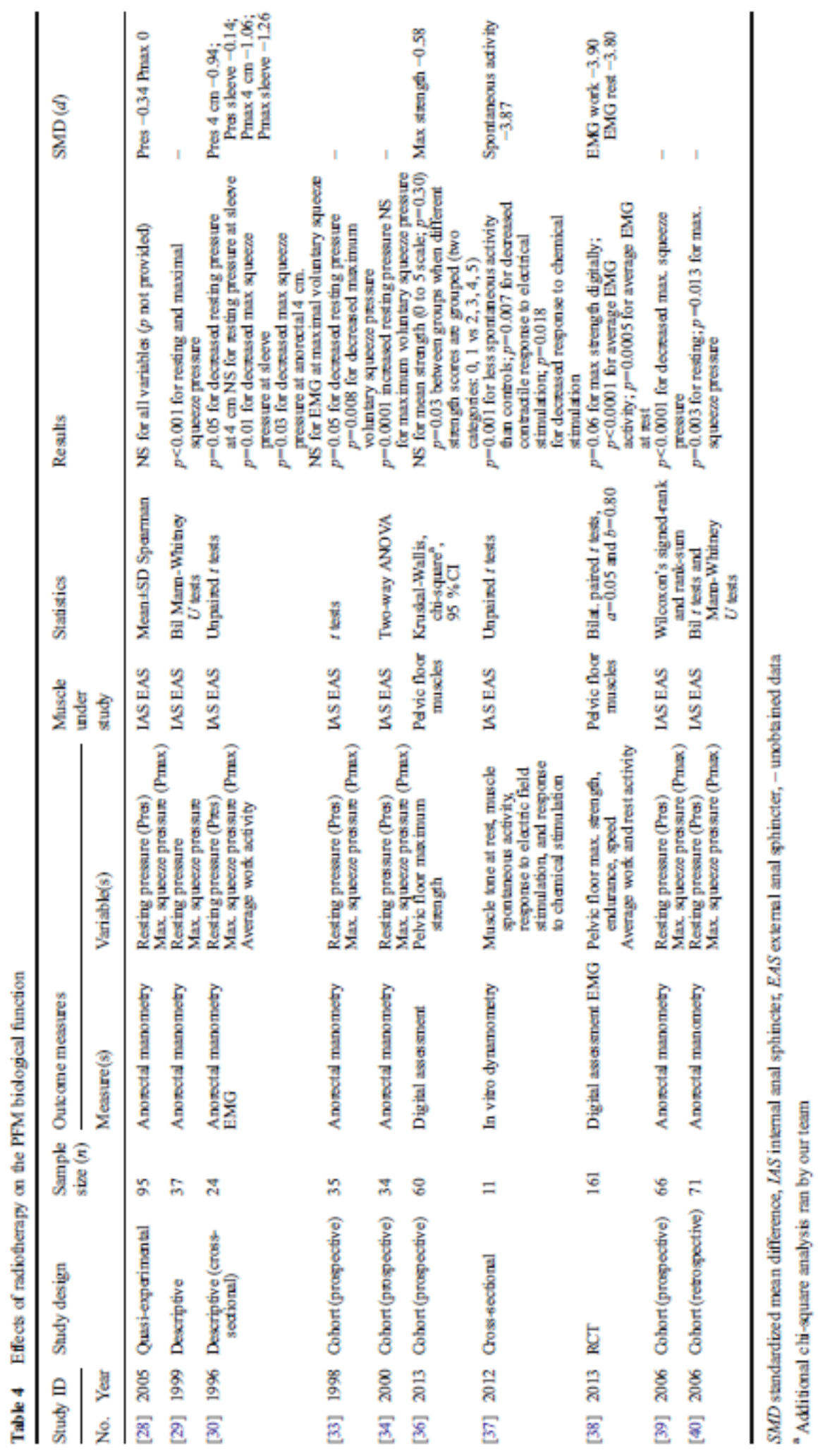


Activity and contractile response of PFMs

In 2012, Lorenzi et al. [37] measured functional changes to the internal anal sphincter after chemoradiation for rectal cancer using drugs and electrical stimulation of sphincter strips in organ baths. The results revealed that the strips from irradiated subjects not only expressed less spontaneous activity than controls but also decreased contractile response to electrical and chemical stimulation. This means that decreased response is not only induced by a neuromuscular injury, but also from injury to the muscle fibers themselves. Dieperink et al. [38] also presented, in the previously discussed RCT, the PFM average activity measured by EMG during a maximal voluntary contraction and found significantly different pre-radiation to postradiation EMG activity measures $(p<0.0001)$, while they did not found significant differences when maximum strength was measured digitally. There was also significant difference ( $p=0.001$ ) between resting EMG activity pre- to post-radiation. However, there was no significant difference in EMG activity during maximum voluntary squeeze in women treated by RT for cervical cancer in comparison to healthy volunteers in the study by Yeoh et al. [30]. Overall, these findings indicate a trend supporting changes in the PFM function after RT in the treatment of pelvic cancers such as prostate, colorectal, and gynecological cancers. Effect sizes could be calculated from five studies $[28,36,38,37,30]$ once the necessary data had been obtained from the authors. The latter two studies show a strong detrimental effect (effect size of -3.8 and -3.9 , respectively) of RT on EMG average resting activity, EMG average work activity, and spontaneous activity for men treated for prostate and rectal cancer [38, 37]. Although, the strong effect sizes obtained from non-significantly different variables reflect possible irregularities in their data distribution. The former three studies on the other hand show weak to strong detrimental effect (effect sizes between -0.14 and -1.26 ) of radiation of muscle resting pressure and maximum squeeze pressure, i.e., maximal strength for men treated for prostate cancer and women treated for cervical cancer $[28,36]$. These effect sizes were not combined together because of the use of different outcome measures to document muscle activity and contractile response of the PFMs.

\section{Discussion}

The purpose of this study was to systematically review the documented effects of RT on the PFM structure and function in pelvic cancer patients. As shown in Tables 3 and 4 , there is some evidence that RT has a detrimental impact on the PFM structure and function. However, few effect sizes were calculable due to missing data. From the available data, it is possible to see that the calculated SDM differed substantially between publications, ranging between -0.72 and 0.17 for effect of radiotherapy on muscle's structure and between -0.14 to -3.91 for effect on muscle's average function. The evidence was scarce with only 13 included studies for the review, and the quality of it was inconsistent (Table 2 ), as previously reported in the review by Ooi et al. [18]. 
Effects of RT on the PFM structure

According to the Oxford Centre for Evidence-Based Medicine [42], there is level 2B evidence that RT affects the structure of the PFMs, between 2 and 62 months after radiation, in a population of men treated with external beam therapy (EBRT) and/or brachytherapy (BT) for prostate cancer. Howbeit, there is also level 2B evidence that these RT-induced changes do not include anal sphincter thickness. Out of the eight articles studying these aspects, only two had excellent methodological quality $[32,34]$. The latter study showed no change of the maximal thickness of the external and internal anal sphincters of men irradiated for prostate cancer, which is corroborated in two other studies of good methodological quality [30, 33]. The former study showed decreased urethral length and increased fibrosis in the levator ani and urogenital diaphragm muscles of men irradiated for prostate cancer. This high-quality cohort study strongly supports a significant effect of RT on structure. Additionally, their choice of outcome measures is fairly robust. Indeed, MRI is a valid measurement tool to assess the structure different muscle layers of the pelvic floor in various planes [43-45]. The levator ani muscle's role is mainly to support organs and resist increased abdominal pressure [46]. Fibrotic tissue could affect its capacity in fulfilling this role. Additionally, the authors controlled for the type of radiotherapy received by the participants and were able to observe that $\mathrm{BT}$ was associated with more changes in these muscles than EBRT. However, the authors did not propose a hypothesis for this phenomenon. It would have been of interest to see if an association existed between the degree of radiation-induced changes and the radiation itself. Close enough, Smeenk et al. published in 2012 a study discussing the relation between the incidence of fecal incontinence to increased radiation dosage to specific muscular layers of the pelvic floor [47]. They found that there are less incontinence complaints when radiation did not target the PFMs, suggesting that the radiation process changed the muscle's integrity. They suggest that to achieve less anorectal complaint after RT, it is necessary to delineate the PFMs anteriorly and plan for $\leq 30$-Gy radiation to the internal anal sphincter, $\leq 10 \mathrm{~Gy}$ to the external anal sphincter, and $\leq 50 \mathrm{~Gy}$ to the puborectalis muscle in prostate cancer patients.

For the other reviewed articles [35, 29, 31, 30, 33], an overall trend toward supporting that radiation affects the PFM structure is presented with a level 4 evidence. The choice of outcome measure was fair: histology was used for one trial, and anal manometry for anal sphincter length's measures in another one. Manometry is shown to be a reliable measure for this variable [48]. These studies failed to present stronger level of evidence mainly because of weak study design $[29,35]$ and moderate $[31,29]$ methodological quality. Only one article did not support the impacts of radiotherapy on the PFM structure such as anal sphincter's length [28]. Even though this study has a good quality of methodology, it needs to be mentioned that the authors did not reveal the radiation protocol received by the subjects. It is impossible to estimate the amount of variability that there could have been in their sample. It is therefore difficult to conclude on the additional influence of radiotherapy to surgery alone on the structure of the anal sphincter from these results. 
Effects of RT on the PFM function

From the ten articles addressing the muscle function aspects, four excellent quality studies (scores from 83 to $96 \%$ ) supported a significant effect of RT on PFM function. In addition to its excellent quality, the study by Dieperink et al. [38] presented the strongest study design: a single-blind randomized controlled trial from which there is level $1 \mathrm{~B}$ evidence that RT affects the PFM function, between 1 and 25 months after radiation, in a population of men treated with intensity-modulated RT for prostate cancer. From supplemental statistics, highly significant differences were found for the EMG average work and resting activity variables, which strongly supports the impacts of RT on PFM function. The study by Lorenzi et al. supports also that there are detrimental effects of radiation on muscle function [37]. Even though their methodological quality was excellent, their cross-sectional study was on a small sample size (total $n=11$ ) and prevented the authors from presenting higher than level 4 evidence. The authors showed, with in vitro dynamometry significantly less spontaneous muscle activity in irradiated muscle strips compared to controls, a decreased number of contractions in response to electrical and chemical stimulation, for anal sphincter strips of men and women treated with RT for rectal cancer. With an excellent methodological quality and a 2B level of evidence, the study of Lim et al. strongly supports that there is a significant decrease in maximal squeeze pressure upon anorectal manometry [39]. Furthermore, the article by Yeoh et al. [34] presented no detrimental effect of RT on PFM function, with a level $2 \mathrm{~B}$ evidence and an excellent methodological quality, in a population of men 1 year post-irradiation for prostate cancer. Surprisingly, their findings showed higher resting pressure than at baseline. Their cohort still reported many PFM dysfunction such as urgency and fecal incontinence, and the unexpected results of anal resting pressure were not further discussed, nor analyzed for confoundings or possible bias. The other reviewed articles [36, 40, 29, 30,33], although most of lesser methodological quality (high dropout rates, younger controls, etc.), all generally point toward detrimental effects of RT on the PFM function. This is in concordance with what was observed by Krol et al. [49] in their systematic review on anal and rectal after EBRT for prostate cancer, where decreased anal resting pressure was supported by low to moderate evidence. Lastly, the study by Allgayer et al. [28] demonstrated no significant differences in PFM function. Again, this study with a good methodology quality is lacking of essential information for results' interpretation.

There are some limits to this review. For instance, it is likely that the quality of the selected studies was slightly overestimated. Indeed, we gave the maximum score for the criterion related to outcome measures when there was a clear description of the outcome used. This was the case for 11 of the 13 selected studies. However, the literature regarding the metrology of the measurement tools was not reviewed. Serving as an example, anorectal manometry was used to measure PFM function in seven studies, yet it is known to lack reliability to measure maximal squeeze pressure $[48,50]$. Digital palpation was used in two other studies [36, 38] but lacks objectivity and precision. Indeed, using palpation as an assessment tool is very accessible and practical but is also limited for appreciating large differences of force [41, 51]. In the study of de Noronha et al. [36], the limited ability of the digital assessment method to detect muscle 
strength with more precision seems to have diminished the potentiality of the authors to bring out the intergroup differences through descriptive statistics. In addition, no differences could be seen with pre- to post-radiation variables when measured digitally in the trial of Dieperink et al. [38], although other measures showed that there was an impact of RT on function from EMG activity for maximal voluntary contraction. In future studies, particular attention should be paid to choose tools with good measurement properties to characterize PFM function, especially to estimate strength and pressure variables. Lastly, we must mention the heterogeneity of cancer types and RT treatment protocols between the articles retained. Although RT to different pelvic organs (prostate, rectum and colon, cervix, etc.) can affect the PFMs in a similar fashion because of their analogous proximity to the musculature and their comparable dose tolerance limits, discrepancies between the effects of different protocols cannot be ignored. This review allows the gathering of existing evidence about measurable PFM changes following RT, despite not being able to shed light on a clear dose-effect relationship between RT and PFMs because of this lack of homogeneity.

Few articles measured the impacts of RT on the PFM structure or function in women treated for gynecological cancers, even though there are many studies reporting urinary, sexual, or fecal problems after radiotherapy versus surgery alone $[4,6,9,12,11,3,52,53]$. In this review, only two papers met our criteria and could be included. Considering the large spectrum of pelvic floor dysfunctions after RT for these female cancers, further research detailing the resulting muscle function seems urgently needed in order to have more readily available treatment options for these problems.

\section{Conclusion}

This systematic review presents some evidence that pelvic irradiation used in the treatment of cancer of the pelvis has detrimental effects on the PFMs, especially on function. There is level $2 \mathrm{~B}$ evidence of these effects on the structure of the PFMs, and these effects do not include change in anal sphincters maximal thickness. There is also level $1 \mathrm{~B}$ evidence of RT effects on PFM function, mainly activity and contractile response during a maximal voluntary contraction when measured by EMG. Further higher methodological quality studies would be needed in order to increase the level of evidence to support this conclusion. The severity of muscle tissue damage and its relationship with the type of radiation or dosage remain unclear. Impacts of RT on the PFMs after gynecological cancer in women also remain understudied. A better understanding of muscle damage and dysfunction following RT will improve medical and rehabilitation interventions targeting the pelvic floor in the future.

\section{Acknowledgments}

Stephanie Bernard was supported by scholarships from the Canadian Institutes of Health Research, the Ordre professionnel de la physiothérapie du Québec, and the Centre for Interdisciplinary Research in Rehabilitation and Social Integration. 


\section{Conflict of interest}

The authors declare that they have no conflict of interest.

\section{Appendix}

Table 5

Additional statistics from the study by Dieperink et al.

\begin{tabular}{|c|c|c|c|c|c|c|}
\hline & \multicolumn{2}{|l|}{ Pre } & \multicolumn{2}{|l|}{ Post } & \multicolumn{2}{|l|}{ Statistics } \\
\hline & $\begin{array}{l}\text { Subjects } \\
\text { (n) }\end{array}$ & $\begin{array}{l}\text { Mean } \\
\text { (SD) }\end{array}$ & $\begin{array}{l}\text { Subjects } \\
(n)\end{array}$ & $\begin{array}{l}\text { Mean } \\
\text { (SD) }\end{array}$ & $\begin{array}{l}\text { Paired ttest } \\
\text { (pvalue) }\end{array}$ & SMD \\
\hline $\begin{array}{l}\text { Maximal } \\
\text { strength } \\
\text { (digital) }\end{array}$ & 160 & $\begin{array}{l}4.01 \\
(0.08)\end{array}$ & 148 & $\begin{array}{l}3.80 \\
(0.09)\end{array}$ & 0.13 & -2.51 \\
\hline $\begin{array}{l}\text { Static } \\
\text { strength } \\
\text { (digital) }\end{array}$ & 161 & $\begin{array}{l}34.42 \\
(1.68)\end{array}$ & 149 & $\begin{array}{l}33.40 \\
(1.77)\end{array}$ & 0.60 & -0.60 \\
\hline $\begin{array}{l}\text { Dynamic } \\
\text { strength } \\
\text { (number of } \\
\text { contractions) }\end{array}$ & 161 & $\begin{array}{l}22.19 \\
(1.18)\end{array}$ & 149 & $\begin{array}{l}20.15 \\
(1.19)\end{array}$ & 0.23 & -1.73 \\
\hline $\begin{array}{l}\text { EMG } \\
\text { (average } \\
\text { during } \\
\text { activity) }\end{array}$ & 156 & $\begin{array}{l}38.21 \\
(1.72)\end{array}$ & 143 & $\begin{array}{l}31.49 \\
(1.37)\end{array}$ & $>0.0001$ & -3.91 \\
\hline $\begin{array}{l}\text { EMG } \\
\text { (average at } \\
\text { rest) }\end{array}$ & 148 & $\begin{array}{l}6.87 \\
(0.32)\end{array}$ & 134 & $\begin{array}{l}5.66 \\
(0.25)\end{array}$ & 0.001 & -3.80 \\
\hline
\end{tabular}

Source: [38]

SMD standardized mean difference 


\section{References}

1. Comité consultatif de la société canadienne du cancer. Statistiques canadiennes sur le cancer 2013. Toronto (Ontario) Canada: Société canadienne du cancer; 2013.

2. Radiation therapy. Canadian Cancer Society. http://www.cancer.ca/en/cancerinformation/diagnosis-and-treatment/radiation-therapy/?region=qc. 2014.

3. Bergmark K, Avall-Lundqvist E, Dickman PW, Henningsohn L, Steineck G. Vaginal changes and sexuality in women with a history of cervical cancer. N Engl J Med. 1999;340(18):1383-9. doi:10.1056/NEJM199905063401802.

4. Donovan KA, Boyington AR, Judson PL, Wyman JF. Bladder and bowel symptoms in cervical and endometrial cancer survivors. Psycho-Oncology. 2014;23(6):672-8. doi:10.1002/pon.3461.

5. Baratiny G, Chiarelli P. Symptoms of lower urinary tract symptoms after prostate cancer treatment. Neurourol Urodyn. 2011;30(6):896-7.

6. Sadovsky R, Basson R, Krychman M, Morales AM, Schover L, Wang R, et al. Cancer and sexual problems. J Sex Med. 2010;7(1 Pt 2):349-73. doi:10.1111/j.1743-6109.2009.01620.x.

7. Alder J, Bitzer J. Gynecological cancer and sexuality. Ther Umsch. 2011;68(10):581-6.

8. Haab F, Beley S, Cornu JN, Culine S, Cussenot O, Hennequin C. Urinary and sexual disorders following localised prostate cancer management. Bull Cancer. 2010;97(12):1537-49.

9. Rutledge TL, Heckman SR, Qualls C, Muller CY, Rogers RG. Pelvic floor disorders and sexual function in gynecologic cancer survivors: a cohort study. Am J Obstet Gynecol. 2010;203(5):514 e1-7. doi:10.1016/j.ajog.2010.08.004.

10. Putta S, Andreyev HJN. Faecal incontinence: a late side-effect of pelvic radiotherapy. Clin Oncol. 2005;17(6):469-77.

11. Bergmark K, Avall-Lundqvist E, Dickman PW, Henningsohn L, Steineck G. Patient-rating of distressful symptoms after treatment for early cervical cancer. Acta Obstet Gynecol Scand. 2002;81(5):443-50.

12. Le T, Menard C, Samant R, Choan E, Hopkins L, Faught W, et al. Longitudinal assessments of quality of life in endometrial cancer patients: effect of surgical approach and adjuvant radiotherapy. Int J Radiat Oncol Biol Phys. 2009;75(3):795-802. doi:10.1016/j.ijrobp.2008.11.018.

13. Ashton-Miller JA, DeLancey JOL. Functional anatomy of the female pelvic floor. In: Bo K, Berghmans B, Morkved S, Van Kampen M, editors. Evidence-based physical therapy for the pelvic floor. 2007. p. 19-33. 
14. Raizada V, Mittal RK. Pelvic floor anatomy and applied physiology. Gastroenterol Clin N Am. 2008;37(3):493-509. doi:10.1016/j.gtc.2008.06.003. vii.

15. Moore K, Dumoulin C, Bradley C, Burgio K, Chambers T, Hagen S, et al. Adult conservative management. In: Paul Abrams LC, Saad K, Alan W, editors. Incontinence. Paris: Health Publication Ltd; 2013. p. 1101-228.

16. Rutledge TL, Rogers R, Lee SJ, Muller CY. A pilot randomized control trial to evaluate pelvic floor muscle training for urinary incontinence among gynecologic cancer survivors. Gynecol Oncol. 2014;132(1):154-8.

17. Yang EJ, Lim JY, Rah UW, Kim YB. Effect of a pelvic floor muscle training program on gynecologic cancer survivors with pelvic floor dysfunction: a randomized controlled trial. Gynecol Oncol. 2012;125(3):705-11.

18. Ooi BS, Tjandra JJ, Green MD. Morbidities of adjuvant chemotherapy and radiotherapy for resectable rectal cancer: an overview. Dis Colon Rectum. 1999;42(3):403-18.

19. World Health Organization. How to use the ICF: a practical manual for using the International Classification of Functioning, Disability and Health (ICF). (ICF). Exposure draft for comment. Geneva: WHO; 2013.

20. Moher D, Liberati A, Tetzlaff J, Altman DG. Preferred reporting items for systematic reviews and meta-analyses: the PRISMA statement. BMJ. 2009;339:b2535.

21. Nout RA, van de Poll-Franse LV, Lybeert ML, Warlam-Rodenhuis CC, Jobsen JJ, Mens JW, et al. Long-term outcome and quality of life of patients with endometrial carcinoma treated with or without pelvic radiotherapy in the post operative radiation therapy in endometrial carcinoma 1 (PORTEC-1) trial. J Clin Oncol : Off J Am Soc Clin Oncol. 2011;29(13):1692-700.

doi:10.1200/JCO.2010.32.4590.

22. Berek J, Hacker N. Berek \& Hacker's gynecologic oncology. Philadelphia: Wolters Kluwer/Lippincott Williams \& Wilkins Health; 2010.

23. Michalski JM, Lawton C, El Naqa I, Ritter M, O'Meara E, Seider MJ, et al. Development of RTOG consensus guidelines for the definition of the clinical target volume for postoperative conformal radiation therapy for prostate cancer. Int J Radiat Oncol Biol Phys. 2010;76(2):361-8.

24. Michalski J, Moughan J, Purdy J, al. e. Randomized trial of 79.2Gy versus 70.2Gy radiation therapy (RT) for localized prostate cancer. J Clin Oncol : Off J Am Soc Clin Oncol. 2015;33((suppl 7; abstr 4)).

25. Kmet LM, Lee RC, Cook LS. Standard quality assessment for evaluating primary research papers from a variety of fields. HTA initiative 1706-7855; \#13. Edmonton: Heritage Foundation for Medical Research; 2004. 
26. Nakagawa S, Cuthill IC. Effect size, confidence interval and statistical significance: a practical guide for biologists. Biol Rev Camb Philos Soc. 2007;82(4):591-605. doi:10.1111/j.1469-

185X.2007.00027.x.

27. Cohen J. Statistical power analysis for the behavioral sciences. Routledge Academic; 2013

28. Allgayer H, Dietrich CF, Rohde W, Koch GF, Tuschhoff T. Prospective comparison of shortand long-term effects of pelvic floor exercise/biofeedback training in patients with fecal incontinence after surgery plus irradiation versus surgery alone for colorectal cancer: clinical, functional and endoscopic/endosonographic findings. Scand J Gastroenterol. 2005;40(10):116875. doi:10.1080/00365520510023477.

29. Vordermark D, Sailer M, Flentje M, Thiede A, Kolbl O. Curative-intent radiation therapy in anal carcinoma: quality of life and sphincter function. Radiother Oncol. 1999;52(3):239-43.

30. Yeoh E, Sun WM, Russo A, Ibanez L, Horowitz M. A retrospective study of the effects of pelvic irradiation for gynecological cancer on anorectal function. Int J Radiat Oncol Biol Phys. 1996;35(5):1003-10. doi:10.1016/0360-3016(96)00147-2.

31. Gervaz P, Hennig R, Buechler M, Soravia C, Brigstock DR, Morel P, et al. Long-term expression of fibrogenic cytokines in radiation-induced damage to the internal anal sphincter. Swiss Surg. 2003;9(4):193-7.

32. Marigliano C, Donati OF, Vargas HA, Akin O, Goldman DA, Eastham JA, et al. MRI findings of radiation-induced changes in the urethra and periurethral tissues after treatment for prostate cancer. Eur J Radiol. 2013;82(12):e775-81.

33. Yeoh EK, Russo A, Botten R, Fraser R, Roos D, Penniment M, et al. Acute effects of therapeutic irradiation for prostatic carcinoma on anorectal function. Gut. 1998;43(1):123-7.

34. Yeoh EEK, Botten R, Russo A, McGowan R, Fraser R, Roos D, et al. Chronic effects of therapeutic irradiation for localized prostatic carcinoma on anorectal function. Int J Radiat Oncol Biol Phys. 2000;47(4):915-24. doi:10.1016/S0360-3016(00)00487-9.

35. Coakley FV, Hricak H, Wefer AE, Speight JL, Kurhanewicz J, Roach IM. Brachytherapy for prostate cancer: endorectal MR imaging of local treatment-related changes. Radiology. 2001;219(3):817-21.

36. de Noronha AF, de Figueiredo EM, de Figueiredo Franco TMR, Candido EB, Silva-Filho AL. Treatments for invasive carcinoma of the cervix: what are their impacts on the pelvic floor functions? Int Braz J Urol. 2013;39(1):46-54.

37. Lorenzi B, Brading AF, Martellucci J, Cetta F, Mortensen NJ. Short-term effects of neoadjuvant chemoradiotherapy on internal anal sphincter function: a human in vitro study. Dis Colon Rectum. 2012;55(4):465-72. doi:10.1097/DCR.0b013e31824154a0. 
38. Dieperink KB, Johansen C, Hansen S, Wagner L, Andersen KK, Minet LR, et al. The effects of multidisciplinary rehabilitation: $\mathrm{RePCa}-$ a randomised study among primary prostate cancer patients. Br J Cancer. 2013;109(12):3005-13.

39. Lim JF, Tjandra JJ, Hiscock R, Chao MWT, Gibbs P. Preoperative chemoradiation for rectal cancer causes prolonged pudendal nerve terminal motor latency. Dis Colon Rectum.

2006;49(1):12-9.

40. Theisen J, Kauer WK, Nekarda H, Schmid L, Stein HJ, Siewert JR. Neoadjuvant radiochemotherapy for patients with locally advanced rectal cancer leads to impairment of the anal sphincter. J Gastrointest Surg. 2006;10(2):309-14. doi:10.1016/j.gassur.2005.04.001.

41. Morin M, Bourbonnais D, Gravel D, Dumoulin C, Lemieux MC. Pelvic floor muscle function in continent and stress urinary incontinent women using dynamometric measurements. Neurourol Urodyn. 2004;23(7):668-74. doi:10.1002/nau.20069.

42. Howick J, Chalmers I, Glasziou P, Greenhalgh T, Heneghan C, Liberati A et al. The 2011 Oxford CEBM evidence levels of evidence (Introductory Document). Oxford Centre for EvidenceBased Medicine. 2011: http://www.cebm.net/index.aspx?o=5653.

43. Tunn R, Delancey JO, Howard D, Ashton-Miller JA, Quint LE. Anatomic variations in the levator ani muscle, endopelvic fascia, and urethra in nulliparas evaluated by magnetic resonance imaging. Am J Obstet Gynecol. 2003;188(1):116-21.

44. Strohbehn K, Ellis JH, Strohbehn JA, DeLancey JO. Magnetic resonance imaging of the levator ani with anatomic correlation. Obstet Gynecol. 1996;87(2):277-85.

45. Kirschner-Hermanns R, Anding R, Stief CG, Najjari L, Bauer RM. Imaging diagnostics of the male pelvic floor. Der Urologe Ausg A. 2013;52(4):527-32. doi:10.1007/s00120-013-3142-4.

46. Avery MD. Current resources for evidence-based practice, March/April 2014. J Midwifery Women's Health. 2014;59(2):210-5.

47. Smeenk RJ, Hoffmann AL, Hopman WP, van Lin EN, Kaanders JH. Dose-effect relationships for individual pelvic floor muscles and anorectal complaints after prostate radiotherapy. Int J Radiat Oncol Biol Phys. 2012;83(2):636-44. doi:10.1016/j.ijrobp.2011.08.007.

48. Freys SM, Fuchs KH, Fein M, Heimbucher J, Sailer M, Thiede A. Inter- and intraindividual reproducibility of anorectal manometry. Langenbeck's Arch Surg. 1998;383(5):325-9.

49. Krol R, Smeenk RJ, van Lin EN, Yeoh EE, Hopman WP. Systematic review: anal and rectal changes after radiotherapy for prostate cancer. Int J Color Dis. 2014;29(3):273-83. doi:10.1007/s00384-013-1784-8. 
50. Lam TJ, Mulder CJ, Felt-Bersma RJ. Critical reappraisal of anorectal function tests in patients with faecal incontinence who have failed conservative treatment. Int J Color Dis.

2012;27(7):931-7. doi:10.1007/s00384-012-1415-9.

51. Bo K, Finckenhagen HB. Vaginal palpation of pelvic floor muscle strength: inter-test reproducibility and comparison between palpation and vaginal squeeze pressure. Acta Obstet Gynecol Scand. 2001;80(10):883-7.

52. Jensen PT, Groenvold M, Klee MC, Thranov I, Petersen MA, Machin D. Early-stage cervical carcinoma, radical hysterectomy, and sexual function. A longitudinal study. Cancer.

2004;100(1):97-106. doi:10.1002/cncr.11877.

53. Nout RA, Putter H, Jurgenliemk-Schulz IM, Jobsen JJ, Lutgens LC, van der Steen-Banasik EM, et al. Five-year quality of life of endometrial cancer patients treated in the randomised Post Operative Radiation Therapy in Endometrial Cancer (PORTEC-2) trial and comparison with norm data. Eur J Cancer. 2012;48(11):1638-48. doi:10.1016/j.ejca.2011.11.014

This is the accepted version of the following article: Bernard S, Ouellet MP, Moffet $\mathrm{H}$, Roy JS, Dumoulin C. (2015) Effects of radiation therapy on the structure and function of the pelvic floor muscles of patients with cancer in the pelvic area: a systematic review. Journal of Cancer Survivorship: Research and Practice, 2016 Apr; 10(2):351-62., which has been published in final form at

http://download.springer.com/static/pdf/213/art\%253A10.1007\%252Fs11764-015-04818.pdf?originUrl=http\%3A\%2F\%2Flink.springer.com\%2Farticle\%2F10.1007\%2Fs 11764-015-04818\&token2=exp=1472480486 acl=\%2Fstatic\%2Fpdf\%2F213\%2Fart\%25253A10.1007\%25252Fs11 764-015-0481-

8.pdf\%3ForiginUrl\%3Dhttp\%253A\%252F\%252Flink.springer.com\%252Farticle\%252F10.1007\%25 2Fs11764-015-0481$\underline{8^{*} \text { hmac }=3 c 3 d 842 a 8826 c c f 5 c 35071 d 13 b 26 a a c d 3171 d 0 c 1 e 308 e c 04071 a b f 9 f 676041 f f}$ 